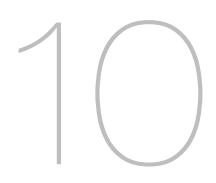

\title{
Asia literacy: A deeply problematic metaphor
}

\section{Ariel Heryanto}

In separate ways, two issues have concerned scholars in Australia and beyond. The first challenge concerns a desire to respond adequately to the widely accepted critique of Euro-American centricism, which is deeply embedded in much of the social sciences and humanities. The second issue hovers around ways to respond to the unsettling impacts of digital technology, which has radically altered our everyday social relations, along with knowledge production, dissemination and preservation. Neither challenge is new. Far from resolving these old issues, however, we have instead been confronted with an even sharper awareness of their complexity. Most of the time, analysts address these issues as two separate areas of inquiry.

Here, I wish to discuss one case, with much broader relevance, where the two issues intersect. I refer to the study of twenty-first-century Indonesia, a former European colony in Asia and Australia's giant neighbour. I look at the problematic notion of 'Asia literacy' as widely used in Australia, across many professions and circles, including the government, the business community and the education sector. I argue that this key phrase is strongly biased, inadvertently recuperating the old Euro-American centricism already disavowed in much of the Western world. The phrase is also unashamedly obsolete in the early twenty-first century, which is marked by the rapid expansion of digital media technology around the globe, not least in Asia. 
Notwithstanding the general admission of its multiple meanings - metaphorically or otherwise - 'Asia literacy' unequivocally articulates the notion of Asia as a fixed text for reading. ${ }^{1}$ Despite the international acknowledgment of Asia's vigorous and dynamic character, including in the White Paper Australia in the Asian Century (Commonwealth of Australia 2012), the phrase assumes that underneath, or superseding, the superanimated Asia exists a more or less coherent, text-like 'Asian' thing (as essence, system or structure), which is assumed to exist 'out there', just waiting to be read, interpreted and commented on by active people who are equipped with the required competency or 'literacy'. In fact, 'reading texts', as a mode of learning shaped by a print-dominated era, is neither the sole nor the best method of learning. This is especially problematic in any discussion of developing knowledge about Asia, and increasingly so in a digitised century. Furthermore, Asia - whatever that might mean - is not, and has never been, simply the muted and helpless object of a reading class of outsiders.

\section{Orality-oriented social life}

Life in Indonesia, as in many other societies around the world, is strongly orality oriented. While most Indonesians are nominally literate, there is a low level of functional literacy. The country has a high official literacy rate: more than 90 per cent. This statistic means that most Indonesians have the ability to recognise the alphabet and mathematical figures. It does not mean, however, that literacy plays a major function in their daily life. Even among the nation's literati and graduates of higher education, many prefer to share important information and messages through face-to-face communication or through new media devices that bear many of the features of orality and conversational communication.

At the turn of the twenty-first century, Sen and Hill reported on publishing in Indonesia:

The book publishing industry in Indonesia is small by regional standards. Through the 1980s Indonesia published 4,000-5,000 titles per year. In 1992, this figure went up to over 6,000, but Indonesia still produced fewer books per head of population than most of its neighbours and even in absolute terms remained lower than South Korea and Thailand, which have much smaller populations. Indonesia's Central Bureau of Statistics ... does not even include book-reading

\footnotetext{
1 'Literally', all words are metaphors, as there is no one-to-one relationship between a word (signifier), its meaning (signified) and the reality to which it refers. There cannot be a truly literal meaning of any word, in the common sense of the words 'literal' or 'literally'. Some words appear to have acquired some literal meanings because their metaphoric qualities have been forgotten, taken for granted or a more recent figurative use of the same word has been introduced successfully.
} 
in its 'socio-cultural' data, which measures the usage of all other media (radio, television, newspapers and magazines) as well as sports and community participation. (Sen and Hill 2000: 24)

Statistics are an inadequate measure of the real situation. In Indonesia, major bookshops keep most newly published titles for no more than three months. Some of the best collections of books are privately owned, and many of these books cannot be found in public or university libraries. No matter where they are kept, books in this tropical country suffer incessantly from extremely high levels of humidity and year-round abundant sunlight, which support the rapid growth of mould, plus various insects and termites. At a more fundamental level, Sen and Hill add a note about the status of books in the country:

Even what constitutes a 'book' is not always obvious. Many published manuscripts in Indonesia, some by respected intellectuals and sold in bookshops, contain no ISBN (International Standard Book Number), which in the context of the international publishing industry is a formal requirement for all books. Some name no Indonesian publisher or printer. (Sen and Hill 2000: 22)

One widely shared post on Facebook is a quote from Albert Einstein (18791955): 'Everybody is a genius. But if you judge a fish by its ability to climb a tree it will live its whole life believing that it is stupid.' If civilisation, intelligence, wisdom or education were measured exclusively in terms of functional literacy and book publishing, Indonesia would be a permanently sad story. One need only think of two of the world's most well-known teachers, who did not put their teachings in written form: Socrates and Jesus. Many scholars have noted that Indonesia is among the slowest and least-developed of its Southeast Asian neighbours in modern schooling, and in university training in the social sciences and the humanities (Booth 1999; Nordholt and Visser 1995). According to some reports, research output (presumably only in English!) on Indonesia authored by non-Indonesians has consistently been several times greater than that by Indonesians (Gerke and Evers 2006). ${ }^{2}$

Indonesia has many talented musicians, with some making headlines in the media beyond the territory of the nation-state, but many of these artists do not read musical notes, including the prominent composer Melly Goeslaw. One of the best poets in contemporary Indonesia is soft-spoken Sapardi Djoko Damono, but his poetry is barely read in the nation, and his published anthology is hard to find in bookshops. More people have heard his name than have read his work. In contrast, the poet Rendra (1935-2009) is one of the best-known

2 Gerke and Evers (2006: 3) make a disclaimer about their data being less than entirely 'true', and their analysis as 'objective'. They base their assessment on data 'from data banks that are maintained in the United States [which] control which scholarly output is regarded as valuable enough to be enshrined in the Social Sciences Citation Index, the Sociological Abstracts, or similar data banks'. 
Indonesian public figures for his performances of poetry reading. Whenever he read his poetry in public, several thousand people listened attentively as if a rock concert. In 1978 and 1990, the militarist regime of the New Order banned Rendra's performances, but none of his books (Murray 1991: 8-9). Indonesia had a blind president, Abdurrahman Wahid (1940-2009), who ruled by hearing and speaking, instead of reading and writing. Except for Sukarno (1901-70), the first president, Wahid was Indonesia's most revered president, both during his life and after his death.

While Indonesia performs poorly in functional literacy, it is outstanding when it comes to engaging with old and new electronic media, whose characteristics (being instant, highly interactive and fluid) resemble the orality mode of communication rather than the literacy mode. The nation is one of the world's largest markets for radio sets (Sen 2003: 586). Today, more than ' $90 \%$ of Indonesians (over 10 years old) account watching television as one of their main social and cultural activities' (Lim 2011: 1). That amounts to more than 220 million people, and 15 per cent of them enjoy the satellite television network (Lim 2011: 2). In 2010 Indonesia was home to the fourthlargest number of Facebook users in the world, rising from rank seven in the previous year. Two years earlier, Indonesia had not been in the ranking. In 2011, however, it jumped to second position (Burcher 2012). According to Sun Jung, 'Indonesian is the third most used language' in the average worldwide traffic of 'K-pop' (Korean popular music) on Google Trends. This can be attributed to the large number of young Indonesian K-pop fans who are 'technology-savvy digital natives who have never known a world without the Internet' (Jung 2011).

In its most basic or primary model, oral communication requires the physical copresence of two or more interlocutors, expressing themselves not only through spoken words but, more importantly, also through intonation, through what is not said and by body language, in specific spatial and temporal conditions of real-time interactions that can never be repeated. Understandably, in such circumstances, life tends to be highly communal, with little or no space for privacy. In today's contexts, such fundamentals have been widely extended and there can be found modified expressions in old and new media that operate in ways reminiscent of oral conversations. Unsurprisingly, emotional icons (emoticons) are essential in short message texting and social media postings among young people, expressing nostalgia for conversations in person.

In the more literacy-dependent societies, the ideas of 'author', 'text' and 'audience' are all clearly separated as autonomous entities. Texts are broken up and clearly marked as separate chapters, sections, paragraphs, sentences, words and characters - as in social life. Marshall McLuhan (1911-80) argued that the 'breaking up of every kind of experience into uniform units in order to produce faster action and change of form (applied knowledge) has been the secret of 
Western power over man and nature alike' (McLuhan 1964: 87). A sacred oath is commonly used to formalise an agreement in an orality-oriented society, just as a written contract is privileged in literacy-dependent nations. Attempting to read quietly in a busy public space is normal in literacy-oriented societies, while it would be taken as strange or antisocial in many other societies, including Indonesia. A literacy-saturated society must verbalise pleasantries such as 'please' or 'thank you', because they can be easily transcribed in writing. In many places across Asia, many of the standard pleasantries are found in constant smiles, giggles and body language, which cannot be coded in the alphabet or punctuation. I will return to the issue of Indonesia's omnipresent smiling in the concluding section.

A common cultural shock confronting first-time foreign visitors to Indonesia is the series of intrusive-sounding questions issued from complete strangers or recent acquaintances: Where are you going? Are you married? Why not? Have you taken a bath? These expressions, like most, are not readily translated into English, but can be crudely understood to mean 'how are you doing?'. Something is fatally lost and something else is unavoidably added in any act of translation.

Obviously, no modern society today is purely orality oriented, literacy dependent or digitally based. Different modes of communication coexist and compete with one another. Many millions of Indonesians travel frequently, do business or spend extended time in literacy-oriented societies, and vice versa. Such experiences can have a far-reaching impact. Therefore, the distinction I suggest here should be taken more as an analytical framework, rather than a set of descriptive empirical categories.

As hinted at above, and contrary to the assumptions made by many children of the Enlightenment, the revolutionary power of new technologies has been more confronting to those in the highly literate societies (Fernback 2003) than to those in the more orality-oriented ones. New media easily finds a warm reception in societies like Indonesia, as it fits well with existing norms and social practices, characterised by fluid, instantaneous and highly collective participatory modes of communication (Heryanto 2010). For all these reasons, 'Asia literacy' is not the best approach to understanding Indonesia, or many other parts of Asia, nor for that matter anything or anyone throughout the world in this century. 


\section{Ways of hearing and seeing}

Marshall McLuhan, in the 1960s and 1970s, was the first to radically challenge some of the most familiar paradigms of understanding the nature of social relations and historical change, in his focus on media technology. In contrast with the past, and currently common, inquiry of what technology has done or can do for social beings, McLuhan and those who followed in his steps were ingeniously concerned with what technology has done or can do to us, and to our ways of understanding the world, others and ourselves. Following McLuhan, I mean by 'technology' the broadest sense of the term, encompassing speech, maps, trains, money or prisons.

Put in the simplest terms, McLuhan identified three major epochs in our history, each marked by one dominant mode of communication in a given society: orality, print and electronic media technology. These are neither three clearly cut nor entirely separable periods or social orders. As mentioned above, and as will be further elaborated and illustrated below, McLuhan was not suggesting a straightforward, linear or uniform view of history, with one phase ending where another one begins. Whether his view represents a technological determinism, as some critics have accused, remains open to debate. Those who built on his early work elaborated his perspective, particularly in the areas concerning the interface between two or more modes of communication.

When a newer technology arrives, the older one never entirely disappears. In order to be accepted by an existing social order, the new technology must be presented in an attractive and non-threatening fashion, even if it later develops in fully fledged ways that undermine and ultimately overthrow older regimes of communication. There is always a complex and dynamic process of interfacing between several modes of communication (orality, print literacy and electronic 'prosumption'/consumption) in most contemporary societies. ${ }^{3}$ The variations of social life based on different interfaced modes of communication form an important but underdeveloped area of study. McLuhan's work provides the foundation for such a study. Being a product of his time, however, his work does not adequately address many of the questions raised after his death at the end of 1980, when the digital world developed far beyond what could be imagined in his time, although still in line with many of his basic premises.

As has been widely documented by many in anthropology, linguistics and literary studies, in the early days of literacy in many societies, people wrote what they had been saying orally since time immemorial. Punctuation was

3 'Prosumption' involves both production and consumption rather than focusing only on production or only on consumption. 
new, awkward, rare and simple. Rhymes, proverbs and a conversational style of speech characterised their writing style, rather than high abstraction and analytical statements. People read texts, including newspapers, aloud. Dialogue in the performing arts was sung. As print was rapidly disseminated, orality continued to function, but had to gradually change its function. People did not cease talking as they learned to read and write. Likewise, pencils and pens have remained part of everyday life in the age of tablets and smart phones. Movies did not vanish, but nor could they survive unchanged, with the invention and rapid diffusion of television, DVDs and YouTube. According to a recent report, although sales of cassette tapes 'have declined, 200,000 albums [were] sold on tape in the U.S. in 2012 - a fraction of a per cent of the 316 million total albums sold but a 645\% increase over 2011 cassette sales' (Rothman 2013: 42).

Orality persisted after the introduction of print. Orality's earlier logic resisted pressure from the print regime, before it underwent transformation and adjusted to a new social environment dictated by the regime of print, in order to survive and remain relevant. As the regime of print consolidated its power, it put more pressure on orality. Ultimately, modern and increasingly literate members of such societies learned how to construct and organise their speech in the way they would eventually compose their words in writing. Rhymes, parables and proverbs faded from speech, or found themselves on the margin of daily intercourse.

The 'ideal type' of change, as outlined above, from one dominant mode of communication to another takes many decades or, more commonly, centuries. The change represents not only or primarily the speed or capacity of communicative technology, 'but alterations in the apparatus through which the world could be "thought" and retrieved in "memory". Furthermore, 'technologies of communication were principally things to think with, moulders of mind, shapers of thought: the medium was the message' (Carey 1998). An overemphasis on the mind and on thought, however, risks overlooking or underestimating the greater impersonal changes in social structures. Such a process of change raises hopes and causes confusion and tension. Apprehension, disorientation and panic were common in North America when television became widely accessible in the middle of the past century (the moment McLuhan's unprecedented thoughts were first published). Recently, another round of overwhelming anxiety occurred when the earlier television generation of the 1960s became older and found themselves confronted by a new, younger generation of this early twenty-first century, who could not keep their hands and eyes off their handheld mobile gadgets twenty-four hours a day, seven days a week. 
James Carey observes that, with the widespread distribution of new electronic recording devices,

the monopoly enjoyed by print was to be exploded and that no one means of experiencing the world would dominate as printing had among educated classes for centuries. The new means of reproducing reality also meant that the historic barriers between the arts and between the arts and other departments of lifeart and science, work and leisure - would be driven down.

... This erosion of barriers between the arts meant as well the erosion of barriers between the audiences. The division of culture into high and low; folk and popular; mass and elite; highbrow, lowbrow, and middlebrow-barriers and distinctions that were themselves the product of printing - would have to be discarded under the impact of new forms of communication which simply did not recognize these distinctions. (Carey 1998)

For some, such change was strongly unwelcome. Few articulated the elitist sentiment of North America at that time more eloquently than Dwight MacDonald in the mid-1950s:

The separation of Folk Art and High Culture in fairly watertight compartments corresponded to the sharp line once drawn between the common people and the aristocracy. The eruption of the masses on to the political stage has broken down this compartmentation, with disastrous cultural results. (MacDonald 1998: 24)

Like nineteenth-century capitalism, Mass Culture is a dynamic, revolutionary force, breaking down the old barriers of class, tradition, taste, and dissolving all cultural distinctions. It mixes and scrambles everything together, producing what might be called homogenized culture, after another American achievement, the homogenization process that distributes the globules of cream evenly throughout the milk instead of allowing them to float separately on top. It thus destroys all values, since value judgments imply discrimination. Mass Culture is very, very democratic: it absolutely refuses to discriminate against, or between, anything or anybody. All is grist to its mill, and all comes out finely ground indeed. (MacDonald 1998: 25)

One major historical product of industrial capitalism and literacy in the West is the notion of 'privacy', along with 'authorship' and the work of authors as 'private property' (McLuhan and Fiore 1967: 122). These notions have been highly valued for at least two centuries. Now it has been made glaringly obvious that privacy has become one of the most vulnerable casualties of the rapid development of digital media. Photocopying machines and digital recorders have undermined copyright as 'private property', and invented the author-cumpublisher. In the wake of whistleblower Edward Snowden's disclosures to the mass media in 2013 about the secret interception operation by the US National Security Agency, surveys suggest that the 
majority of Americans support the [government operation], even if they don't entirely trust the government's explanations. According to a recent Washington Post/ABC News poll, after digesting Snowden's news, a solid majority feel that it's more important to fully investigate terrorist threats than to protect personal privacy. (Wolf 2013: 39)

Many Americans tolerated their privacy being compromised, not only because of the real or perceived threats of terrorism or because the state apparatuses are considered too powerful to resist, but also because, as Wolf puts it aptly, '[p]rivacy is not the only illusion in the new age of data; government secrecy is too. Big Brother might be watching, but he is also being watched' (Wolf 2013: 39) — as the cases of Bradley Manning, Wikileaks and Snowden illustrate. We live in a village-like world: a global village.

Of course, years before Snowden made the headlines, privacy had already been rendered obsolete for millions of Facebook users around the world. Regularly, I have witnessed couples who have been married happily for decades post messages or photographs about each other's appearance or daily activities, and post such comments for the whole world to see. Someone told me how her friend took a picture of a meal in a restaurant with her mobile device and posted it on Facebook for the general public. Instantaneously, her companion sitting across the table commented on the posted image on the same social media platform. While preparing this chapter, a well-respected public figure in Indonesia posted on Facebook a series of his own medical reports just issued from a hospital where he had undergone serious clinical examination!

Changes to the notion, status and value of privacy are not taking place everywhere at the same time and in the same way for all people. These variations do not adhere to simple political, economic, national lines or exist exclusively among specific age groups. This is well illustrated by how Facebook operates, and explains why it is so overwhelmingly popular, transcending so many of those familiar categories. Lev Grossman (2010) recalls that '[p]eople hated Facebook's News Feed when it was introduced in 2006. They thought it was creepy and intrusive ... and now Facebook is unimaginable without it.' Chris Cox, Facebook's vicepresident, elaborated further in an interview with Grossman:

When caller ID came out, people went psycho. You know, because, Oh my God, now people are going to know I'm calling them! This is terrible! I'm going to end up being tracked, and Big Brother and Orwell and all that! The reality is now you won't pick up a call unless you know who's calling you. (Grossman 2010)

The introduction of electronic media technology and its impact have generated tensions and social change comparable with earlier societies hit by the spread of literacy and print. They are not, however, and never can be, a full repeat. The process varies across different societies, and thus its impact varies as well. 
The impact of digital media has been harsher and more painful for highly literacy-dependent societies than for strongly orality-oriented societies. We are not, therefore, witnessing a kind of technological determinism. There is no suggestion of a deterministic, uniform or linear history that all societies undergo - from orality to literacy to the new media participation often dubbed 'prosumerism' (the amalgamation of producer and consumer).

\section{New ways of learning about the new world}

Australian universities are committed to upholding the privacy protections of participants in their respective sponsored research projects. A national body regulates and oversees a mandatory and meticulous formal review of ethical issues in all research plans. All of this is commendable, but its operation often requires more flexibility than many university human research ethics committees are willing or able to accommodate. This is especially true for social research conducted in many parts of Asia, where the notion of privacy is non-existent, irrelevant or significantly different from that generally understood in Australia and most Western societies.

I am aware that to suggest some variation between daily life in Australia (notionally conceptualised as a Western society) and Asia (the 'East') can be easily misconstrued as recuperating the old-fashioned and false dichotomy of East versus West. To suggest, however, that all of these societies are flatly and universally homogeneous would be ridiculous. One alternative approach to identifying and analysing social variations beyond the East/West divide is to take into account the configuration or interfaced modes of communication across social collectives. This technologically based category is to complement, and not substitute, the already familiar practice of categorising social life along 'economic organization (mercantilism, industrialism, capitalism, socialism) or politics (the divine right of kings, the social contract, the dictatorship of the proletariat)' (Carey 1998), or nation-state categories.

Like nations, prisons and factories, our schools and universities are very much products of the logic of the old print technology in Europe and North America. These institutions are currently struggling to survive the overwhelming impact of digital media technology on learning environments, which has made it not only imaginable and possible, but also desirable, to teach and learn in a classroom without walls, without a fixed class timetable and, not least of all, without the hassles of finding a car parking space. This new environment changes not only where, when or how we learn things, but more importantly, what we learn and why. In ways comparable with the struggle of the church in Europe when confronted by the spread of print and the translation of sacred words into 
vernacular languages several centuries ago, universities today have tried hard to manage their situation in order to salvage the old, established notions of certified knowledge, authority and ethical integrity by incorporating digital media technology into knowledge production and dissemination. Sooner or later we will regard such efforts as similar to insisting that a computer mouse is a new kind of pen or a mobile tablet device is a new kind of book.

Those who run schools and universities have gradually acknowledged that this new media technology does not simply offer options for learning, but rather asserts its logic and forces educational institutions to change the way things are done in the administration office, in classrooms and on campus grounds. Few, however, perceive the power of the technology to undermine some of the key fundamentals of the establishment and operation of these modern institutions and, for better or worse, to transform them into something radically different. In the view of McLuhan and Fiore:

Today's television child is attuned to up-to-the-minute 'adult' news-inflation, rioting, war, taxes, crime, bathing beauties - and is bewildered when he enters the nineteenth-century environment that still characterizes the educational establishment where information is scarce but ordered and structured by fragmented, classified patterns, subjects, and schedules. (McLuhan and Fiore 1967: 18)

Regardless of the tactics employed by old regimes against change, one need only look at the mass media industry to envisage what transformation our universities might experience in the future. When the form and function of print media initially intersected with online space, print products were simply reproduced in digital form on websites. Similarly, many university lecturers simply uploaded their text in pdf (portable document format) on the course website - just as early writers composed in rhymes and proverbs. Before long, universities realised that the new media did not simply extend their old operations and products into a new online space. Now, the new media not only alters the content - as journalists increasingly gather information initially or exclusively from the Internet - but also the websites feature a set of completely new materials such as interactive graphics, audio and video materials, and realtime coverage, which were all non-existent in earlier forms of the industry.

The fact that McLuhan's work has not been taken more seriously and applied more broadly across the social sciences and humanities, beyond media studies in his home base of Canada, suggests that his insights were far ahead of his time. To gauge how slow and conservative our intellectual capacity has been to grapple with the full potential and impact of digital media, it is useful to look back at our efforts in coming to terms with the significance and consequences of print. Six centuries after Johannes Gutenberg invented movable-type printing, we are still struggling to critically comprehend and fully grasp the impact of 
print technology on human history. Only in the late twentieth century did we seriously engage in the debate on how literacy and print capitalism might be foundational in the creation of nations, following the publication of Benedict Anderson's Imagined communities. To be fair, it must be remembered that Anderson's arguments are far more complex and nuanced than can be summed up here. For our immediate concerns, let us focus on one of his central arguments concerning the 'genesis of nationalism' (Anderson 1983: 30).

Anderson attributes the birth of nations to a series of historical conditions related to the decline of sacred communities. In his view, '[b]eneath the decline of sacred communities, languages and lineages, a fundamental change was taking place in modes of apprehending the world, which, more than anything else, made it possible to "think" the nation' (Anderson 1983: 28). He was referring to the 'idea of simultaneity' (emphasis in the original), and argues that

[w] hat has come to take the place of the mediaeval conception of simultaneityalong-time is, to borrow again from Benjamin, an idea of 'homogeneous, empty time,' in which simultaneity is, as it were, transverse, cross-time, marked not by prefiguring and fulfilment, but by temporal coincidence, and measured by clock and calendar ... The idea of a sociological organism moving calendrically through homogeneous, empty time is a precise analogue of the idea of the nation, which also is conceived as a solid community moving steadily down (or up) history. (Anderson 1983: 30-31)

It is significant that Anderson published his innovative work only in the early 1980s, to widespread interest. In other words, it was only after computers had become a daily necessity to many professionals in major industrial centres around the globe. Only then could scholars find themselves in a better position to analyse the conditions under which a new conception of homogeneous time prevailed and nations were born. It is only after word processing, the Internet and mobile media communications began to impact significantly on the sense and sensibilities of a centuries-long print regime that people have been properly equipped to undertake a critical examination of what print has done to human beings across the globe, rather than for them.

In line with most anti-humanist theorists of the twentieth century, Anderson's portrayal of the nation is conceived as a product not primarily of human efforts. Rather, certain historical conditions and media technologies have required and enabled the articulation of new forms of solidarity, new aspirations and social orders that have found their expression in 'nations'. Referring to 'the novel and the newspaper', he asserts that they 'provided the technical means for "re-presenting" the kind of imagined community that is the nation' (Anderson 1983: 30; emphasis in original). 
We should not, however, stop there. A couple of decades after this new awareness of what print might have done to human history, we still cannot say with full confidence that the print regime is fully under our gaze and an object of our analysis, detached from our analytical framework. Anderson's subsequent thesis about 'long-distance nationalism' is an intriguing case in point, because it betrays some of his earlier thesis. If he is correct about the potency of specific media technology for transforming human history-in this case, the critical contribution made by print media, such as the novel and the newspaper, to the birth of nations - in the wake of the spread of electronic media, one would expect Anderson to anticipate the decline of nations and nationalism, and imagine the rise of a new consciousness in human history, new conceptions of time and space, with radically new communities and forms of solidarity ('post-nation' is an inadequate metaphor, but suggestive). Instead, he argues that the new media has generated only a new version of nationalism called 'long-distance nationalism':

It would be very difficult to say that today Indian nationalism is less serious than Chinese, East Timorese [less] than Thai, Indonesian [less] than Japanese, or Taiwanese [less] than Korean. If one asks why this should be so, especially today, an explanation is impossible without thinking about the role of the electronic media, which for most people now exercise[s] an even more powerful influence than print, the original mother of nationalism.

... One could even argue, as I have done in another context, that electronic communications, combined with the huge migrations created by the present world-economic system, are creating a virulent new form of nationalism, which I call long-distance nationalism: a nationalism that no longer depends as it once did on territorial location in a home country. (Anderson 2001: 42)

If the electronic media fundamentally enhances nationalism, there should be another and more critical re-examination of the thesis about the fundamental service of print literacy in the birth of nations.

For McLuhan and Fiore (1967: 45), '[t]he rational man in our Western culture is a visual man. The fact that most conscious experience has little "visuality" in it is lost on him.' Consequently:

They suspect the ear; they don't trust it. In general we feel more secure when things are visible, when we can 'see for ourselves'. We admonish children, for instance, to 'believe only half of what they see, and nothing of what they hear'. All kinds of 'shorthand' systems of notation have been developed to help us see what we hear.

We insist on employing visual metaphors even when we refer to purely psychological states, such as tendency and duration. For instance, we say thereafter when we really mean thenafter ... We are so visually biased that we call our wisest men visionaries, or seers! (McLuhan and Fiore 1967: 117) 
This is not to say that people in less literacy-oriented societies are not biased or are less biased. Rather, we are differently biased, and more often than not we are all unaware of our own biases. For these reasons, cross-cultural experience is both potentially risky and enriching. Australia's commitment to understanding Asia and deeply engaging with Asians in various forms is highly commendable, not least for allowing Australians to better understand themselves in the process of learning about 'others'. This can be done successfully if Australians let go of the Asia literacy paradigm, and seek new and better approaches to 'reading' Asia and Asians as other than text-like characters (in the double sense). One step in that direction is to acknowledge some of the fundamental differences in daily life between many parts of Asia with strong orality-oriented features and those in other parts of the world such as Australia. I wish to conclude with a couple of cases to illustrate these differences.

\section{Politically incorrect habits}

It is normal for first-time foreign visitors, unless they come from similar social environments, to misunderstand how and why certain things are done in Indonesia. One well-documented example is the strong reaction by many Indonesians and many other Asians to the widely published image dated 15 January 1998 of Michel Camdessus, then International Monetary Fund (IMF) managing director, with his arms folded, standing and watching then president Suharto of Indonesia bowing to the table as he signed the country's bailout package. In another case, Australians were outraged at the published image of Amrozi, one of the Bali bombers, smiling along with the Indonesian police in 2002. I wish to argue that in both cases a misunderstanding took place, in part due to the work of different modes of communication and the materiality of language - being one of the oldest media technologies in our history - and its impact on our often taken-for-granted banal sensibilities, norms and social values.

By the late 1990s, a great number of Indonesians (including the military elite and not just the student political activists who took to the streets) felt that they had had more than enough of Suharto's rule. Whether the 1998 IMF bailout package was wise has been a topic of debate, which is not our immediate concern here. What is of concern is Camdessus's posture in the image. Remarkably, despite the widespread repugnance to the aged dictator and impatience to be rid of Suharto, many Indonesians and their neighbouring nationals took offence at Camdessus's posture. Significantly, most angry Indonesians did not express their feelings in writing. 
Ten years after the infamous picture was published, Chris Giles (2007) commented on the photo as he looked back and offered further analysis of the merits of the bailout package: 'For Asia, Mr Suharto's humiliation and subsequent downfall after more than 30 years in power symbolised the domineering attitude of the west.' In response to Giles, Dennis de Tray of the Center for Global Development (in Washington, DC) wrote a letter to the magazine and concluded his note with these words:

I have always found it profoundly unfair that someone [Camdessus] who went out of his way to support what we all saw as a last ditch effort to save Indonesia has been pilloried simply because he stood where he was told to stand, and has the same habit I have: he folds his arms when he is standing. (de Tracy 2007)

While many Asians found Camdessus's posture offensive, only those who spoke Indonesian could have had an additional insight into what makes the posture offensive. Indonesian has a popular idiomatic expression 'berpangku tangan' (fold one's arms), referring to the state of being selfish, lazy or uncaring about the plight of others in their immediate environment. To fold one's arms is usually seen as a display of power and arrogance in Indonesia, an orality-oriented society, where communal solidarity is supposed to be highly valued. By no means is this to suggest that Indonesians are generally any more sociable and charitable than anyone in Australia or elsewhere. In fact, people with disabilities, the elderly and pregnant women are generally treated more kindly in public spaces in Australia than in Indonesia. Pedestrians are better respected on zebra crossings on Australian streets than in Indonesia. In Indonesia, however, one is expected to not fold one's arms in front of someone else in a difficult situation, even if one has no interest in assisting those in difficulty.

To some extent, de Tracy is correct that it is hard to blame common habits, especially when such habits are not considered bad or offensive in their home environment. It is only fair that such respect and understanding are shown reciprocally. Smiles and a few giggles are a common habit across many societies including in Indonesia, Malaysia, Thailand, Burma and Vietnam, where oral culture is commonly strong. In these cultures, smiling does not necessarily signify being happy, amused or friendly. Smiles and giggles are considered to go well with any topic of conversation, including about a vacation, having just escaped a traffic accident, a recent illness or the death of a loved one. I have met some Indonesians who cannot utter a complete sentence without a burst of giggles, regardless of the topic of conversation. Many foreigners in Indonesia are often offended when they have minor accidents, such as stumbling or falling to the ground, because Indonesians will laugh heartily when witnessing the accident. Smiles and giggles are so deeply ingrained in daily interactions in Indonesia - just as bowing is in Japan - that most Indonesians are not even 
aware of their own or others' smiles. In everyday conversations with fellow Indonesians, what would strike them is a lack or total absence of such smiles, suggesting the other party may be experiencing pain, serious sadness or anger.

My first overseas trip was to the United States as an exchange student for a year. It struck me that it was not usual for American people to smile, unless there was something that made them happy or amused. In public places, I noticed some grumpy-looking people wore a pin with an icon and text that says 'smile'! You needed to be literate to read and appreciate it. As an exchange student in a public high school, I took a speech class, where students had to make short speeches in front of the class every week. Our teacher assessed, analysed and commented on each presentation. One unexpected criticism that I received from the teacher - and the only one that I will remember for the rest of my life - was that I smiled 'too much' when speaking, and smiled when there was nothing funny. Since then, I consciously worked very hard to learn not to smile 'too much'. I was not aware of the consequences until a long-distance call from a relative, who giggled when I told him that I was suffering from a bad cold. I was puzzled, but not offended. For the first time, I had the ability to hear the typical and 'strange' Indonesian giggles that shock and puzzle many foreigners.

All of the above came back to mind in November 2002, when I followed the uproar in Australia in response to the published image of the Bali bomber Amrozi smiling during an interview in Denpasar (Bali) with Indonesia's police chief. Amrozi was eventually executed in 2008, but this smiling incident hit the media headlines in Australia, and became the source of a major public outcry. Significantly, no Indonesian media showed interest in the incident. After all, this is a country that had recently emerged from more than three decades of military dictatorship under Suharto, who was known as the 'smiling general', and who came to power in the wake of the massacre of nearly one million people in 1965-66. The Indonesian public and media, including the Bali Post, were neither impressed nor disturbed by Amrozi's smile. Indonesia's largest daily, Kompas, took some interest - not in the controversial smiles, but in Australia's response to them. It ran a piece of news with the headline 'Gambar Amrozi tersenyum timbulkan kemarahan Australia' (The image of Amrozi smiling provoked Australia's outrage) (Kompas 2002).

Several sympathetic Australian journalists and Indonesian commentators have offered explanations about the disturbing scene to the Australian public. Most attribute it to 'cultural differences' between the two countries, exacerbated by the difficult circumstances in which the Indonesian police operate. Those giving cultural explanations stressed that Australians might well have failed to understand that smiling in the Indonesian context does not necessarily imply delight, amusement, friendliness or malice. I have no objections to such cultural explanations, but I have discord with those who attempted to infer 
a rationalist reason in the smiles; such explanations were provided in effect to demonstrate the 'objective rationality' behind the smiles. The smiles were interpreted as if they were some kind of calculated strategy on the part of the suspect and his captors to achieve political gains or to hide embarrassment.

In light of what I have discussed above, I am sure Amrozi smiled unconsciously. No calculation, clever or otherwise, was involved. More precisely, the bomber and the police smiled because they could not help it, because that was the way they had been brought up since childhood - similar to Camdessus folding his arms. The Indonesian public took no issue with the smiles, either because these smiles appeared insignificant or because the public simply failed to notice them. As Pierre Bourdieu remarked, culture is what goes without saying, just as it comes without questioning (1977: 166-7).

In many orality-oriented languages in Indonesia, smiles are built-in, just as tenses or gender are in European languages. Neither gender nor tense exists in Indonesian grammar. One common pitfall for most native English speakers (including Australians) who learn Indonesian is in pronouncing words that start with $/ \mathrm{c} /, \mathrm{j} /, \mathrm{p} /$ or $/ \mathrm{t} /$. In English these phonemes are aspirated consonants, while in Indonesian not a single consonant is aspirated. To pronounce words such as 'Jakarta' in Indonesian properly, native speakers of English must make an extra effort to spread one's lips widely enough. In other words, like it or not, one has to smile as one speaks, without expressing a sense of delight or amusement.

One wonders whether Amrozi's smile would have provoked such a strong reaction from the Australian public if more Australians had fluency in instead of 'knowledge about' Indonesian language and culture. Australia's commitment to Asia literacy includes a greater commitment to learning four priority Asian languages, including Indonesian. However, the foregoing suggests that Australians will enhance their knowledge capacity and learn a lot more about Indonesia, and consequently themselves, by learning to listen and speak the language, instead of trying to 'master' the language and become highly 'literate' by focusing on written texts.

\section{References}

Anderson, Benedict. 1983. Imagined communities: Reflections on the origin and spread of nationalism. London: Verso.

Anderson, Benedict. 2001. Western nationalism and Eastern nationalism: Is there a difference that matters? New Left Review 9(May-June): 31-42. 
Booth, Anne. 1999. Education and economic development in Southeast Asia: Myths and realities. Paper delivered at the Second International Malaysian Studies Conference. 2-4 August, University of Malaya, Kuala Lumpur. URL: phuakl.tripod.com/pssm/conference/Anne_Booth.htm. Consulted 7 December 2014.

Bourdieu, Pierre. 1977. Outline of a theory of practice. Trans. Richard Nice. Cambridge: Cambridge University Press.

Burcher, Nick. 2012. Facebook usage statistics by country December 2008December 2011. 4 January. URL: www.nickburcher.com/2012/01/facebookusage-statistics-by-country.html. Consulted 4 April 2012.

Carey, James. 1998. Marshall McLuhan: Genealogy and legacy. Canadian Journal of Communication 23(March). URL: www.cjc-online.ca/index.php/journal/ article/view/1045/951. Consulted 10 August 2013.

Commonwealth of Australia. 2012. Australia in the Asian Century. White Paper. Canberra: Commonwealth of Australia. URL: asiancentury.dpmc.gov.au/ white-paper. Consulted 7 October 2013.

de Tray, Dennis. 2007. A clearer picture of the day Suharto signed. Financial Times 5 July.

Fernback, Jan. 2003. Legends on the net: An examination of computer-mediated communication as a locus of oral culture. New Media and Society 5(1): 29-45.

Gerke, Solvay and Evers, Hans-Dieter. 2006. Globalizing local knowledge: Social science research on Southeast Asia, 1970-2000. Sojourn 21(1): 1-21.

Giles, Chris. 2007. Wrong lessons from Asia's crisis. Financial Times 2 July.

Grossman, Lev. 2010. Mark Zuckerberg. Time 15 December. URL: www.time. com/time/specials/packages/article/0,28804,2036683_2037183_2037185,00. html. Consulted 4 April 2012.

Heryanto, Ariel. 2010. Entertainment, domestication, and dispersal: Street politics as popular culture. In Edward Aspinall and Marcus Mietzner, eds. Problems of democratisation in Indonesia: Elections, institutions and society. Singapore: ISEAS.

Jung, Sun. 2011. Race and ethnicity in fandom: Praxis K-pop, Indonesian fandom, and social media. Transformative Works and Cultures(8). doi:10.3983/ twc.2011.0289. Consulted 7 January 2012. 
Kompas. 2002. Gambar Amrozi tersenyum timbulkan kemarahan Australia. Kompas 15 November. URL: www.kompas.co.id/kompas-cetak/0211/15/ln/ gamb02.htm. Consulted 15 November 2002.

Lim, Merlyna. 2011. @crossroads: Democratization and corporatization of media in Indonesia. URL: participatorymedia.lab.asu.edu/files/Lim_Media_ Ford_2011.pdf. Consulted 7 December 2014.

MacDonald, Dwight. 1998 [1957]. A theory of mass culture. In John Storey, ed. Cultural theory and popular culture: A reader, 2nd edn. Athens: The University of Georgia Press.

McLuhan, Marshall. 1964. Understanding media, 2nd edn. New York: McGraw-Hill.

McLuhan, Marshall and Fiore, Quentin. 1967. The medium is the massage. New York: Bantam Books.

Murray, Alison. 1991. Kampung culture and radical chic in Jakarta. RIMA 25(Winter): 1-16.

Nordholt, Nico Schulte and Visser, Leontine. eds. 1995. Social sciences in Southeast Asia: From particularism to universalism. Amsterdam: VU University Press.

Rothman, Lily. 2013. Rewound. Time 19 August: 41-43.

Sen, Krishna. 2003. Radio days: Media-politics in Indonesia. The Pacific Review 16(4): 573-89.

Sen, Krishna and Hill, David. 2000. Media, culture and politics in Indonesia. Melbourne: Oxford University Press.

Wolf, Michael. 2013. Privacy is mostly an illusion. Time 19 August: 36-39. 
This text is taken from The Social Sciences in the Asian Century, edited by Carol Johnson, Vera Mackie and Tessa Morris-Suzuki, published 2015 by ANU Press, The Australian National University, Canberra, Australia. 